\title{
Jet ignition in small two-stroke engines: an experimental survey on benefits and challenges
}

\author{
Lorenzo Bosi ${ }^{1}$, Marco Ciampolini ${ }^{1}$, Sandro Raspanti ${ }^{1}$, Luca Romani $^{1}$, and Giovanni \\ Ferrara $^{1, *}$ \\ ${ }^{1}$ Università degli Studi di Firenze, Department of Industrial Engineering, Via di Santa Marta 3, 50134 \\ Firenze, Italy
}

\begin{abstract}
Increasingly stringent policy on carbon dioxide have proved to be a severe constraint on the design of light two-stroke (2S) engines. The enhancement of efficiency is claimed to be the main target to make these devices compliant with future regulations. Low-Pressure Direct Injection (LPDI) was found to be effective in the reduction of fuel short circuit, thus improving efficiency and mitigating pollution. Innovative combustion technologies are required to exploit further the fuel potential. Jet Ignition (JI), i.e., ignition provided by means of hot turbulent jets, was found to improve the fuel ignition process, leading to a faster and more uniform combustion. Several benefits are shown in over forty years of Literature, from the higher performance to wider flammability limits. However, few studies have been performed on small $2 \mathrm{~S}$ engines, for which only full-load data are available. This paper aims at experimentally evaluating benefits and challenges of adopting the JI technology on light 2S LPDI engines at both full- and low- load operation. Different configurations of passive prechambers have been investigated in terms of indicated cycle, brake efficiency and cycle-to-cycle variation. A sensitivity analysis on the spark timing was performed to fine-tune the combustion process. Results show the adequacy of the JI for use in devices operating close to full torque, like garden tools; however, issues related to the excessive amount of residual gas or to the rapid pressure decrease during the expansion phase were highlighted. Different solutions for solving these challenges are proposed.
\end{abstract}

\section{Introduction}

High power density, light weight, small market price, minimal maintenance requirements, simplicity of construction and high reliability are typical features of two-stroke (2S) engines, which make them well-suited for several applications, from motorcycles to professional garden equipment. However, the high fuel consumption and unburned hydrocarbons emissions conflict with the increasingly stringent international environmental policy. The reason of these issues relies on the layout of transfer and exhaust ports, which leads to the loss of a significant amount of unexploited fuel at high engine loads, and to a noticeable cycle-to-cycle variation at low loads due to poor cylinder scavenging [1].

\footnotetext{
*Corresponding author: giovanni.ferrara@unifi.it
} 
Direct injection was found to be effective to reduce the fuel short circuit phenomenon, since fuel is introduced in the cylinder separately from the scavenging air. Some of the Authors carried out several numerical and experimental studies on a $300 \mathrm{~cm}^{3}$ engine, evaluating both High-Pressure (HPDI) [2,3] and Low-Pressure (LPDI) [4-7] injection strategies. In particular, a consistent reduction of fuel consumption and pollutant emissions was observed by adopting the LPDI from mid-to-high engine loads, even if the weak flow field was found not to be able to sufficiently homogenise the fuel droplets at low loads, increasing further cycle-to-cycle variation.

Innovative combustion techniques are required to improve further the exploitation of the fuel potential while reducing low-load challenges. Jet Ignition (JI), also called Torch Ignition (TI), seems to be one of the most promising technology to achieve this goal. In the JI combustion, the fuel-air mixture inside the combustion chamber is ignited by means of hot turbulent jets coming from a secondary small combustion volume, i.e., the prechamber. The combustion process starts in the prechamber by means of a spark plug; then, the hot turbulent jets, composed of partially burned gas or real flames, enter the main combustion chamber promoting turbulent phenomena of heat and mass transfer, thus leading to a faster and more uniform combustion process. These phenomena were found to be able to ignite leaner fuel-air mixtures, moving toward the Low Temperature Combustion (LTC).

Several works can be found in the Literature for more than forty years of numerical and experimental investigations. In particular, passive prechambers, devoid of a dedicated injector, which are claimed to be well suited for $2 \mathrm{~S}$ engines due to the low complexity and limited costs, have been widely studied in carburettor and PFI engines for automotive use [8-14]. Results showed a marked increase in the slope of the HRR curve [11,15] which leads to improved combustion and indicating efficiencies, allowing us to decrease the fuel consumption [11,13]. Benefits in terms of NOx [9,16], HC [9,11,17] and CO [12,13] were also highlighted. However, passive prechambers were found to be unstable in PFI fuel-lean engines [13]. For this reason, direct injection technologies have been investigated in the Literature [18-23]. The fuel stratification that can be achieved by means of dedicated injection strategies [21,23] or unconventional piston bowls [18-20] allowed to reduce further the equivalence ratio in the cylinder without worsening cycle-to-cycle variation, thus lowering the fuel consumption $[19,20,22]$.

Notwithstanding the promising results provided from the Literature, applications for civil/commercial use are nowadays absent, and only few studies have been performed on small 2S gasoline engines, for which experimental data are available at full-load condition only $[14,24]$.

The present paper aims at evaluating the benefits and challenges of adopting the JI combustion technology on small $2 \mathrm{~S}$ gasoline LPDI engines for commercial use, in order to understand its applicability on low-weight appliances, e.g., motorcycles, chainsaws, blowers, brush cutters, and drones.

Different passive prechambers have been installed on a LPDI protype derived from a Piaggio $49.2 \mathrm{~cm}^{3}$ engine and tested on the engine test-bench facility of the Department of Industrial Engineering of the University of Florence. Different prechamber geometrical layouts have been investigated varying number and diameter of orifices, prechamber volume and depth of entry into the cylinder head, so as to evaluate the effects of the JI combustion on the indicated cycle, brake efficiency, cycle-to-cycle variation, and ignition effectiveness. Both full-load and low-load conditions at different engine speeds have been investigated in order to reproduce engine conditions during real operation. A sensitivity analysis on the spark timing was carried out to achieve the highest BMEP at high engine load and best brake efficiency values at low loads. 


\section{Materials and methods}

The experimental campaign for the feasibility evaluation of applying the JI combustion on small $2 \mathrm{~S}$ engines was carried out at the engine test-bench facility of the Department of Industrial Engineering of the University of Florence. The passive prechambers were tested on a LPDI prototype (Figure 1a) derived from a Piaggio 2S single cylinder air-cooled 49.2 $\mathrm{cm}^{3}$ engine for motorcycle application. The baseline LPDI engine is characterized by a compression ratio of 10.5:1. An IC02NIj Continental injector was installed on the cylinder liner, few millimetres above the central transfer duct (Figure 1b); injection pressure was set to 5 bar. Gasoline was supplied to the injector by means of an external electric pump. Lubricating oil was added separately in the intake manifold by means of an electrically driven Dell'Orto reciprocating pump. The pump was managed by the ECU by means of a dedicated map, in order to provide the right amount of oil as a function of engine speed and load. The values of Spark Timing (IGA) and Start of Injection (SOI) of the baseline LPDI engine have been set to achieve the highest BMEP values at full-load conditions; on the contrary, the calibration phase at low loads was instead performed to achieve highest efficiency values. A BR8ES M14 spark plug was installed on the baseline engine head; in the JI configuration instead the prechamber was screwed in the pre-existing hole (Figure 1c) and an ER9EH-6N M10 spark plug was host in the prechamber internal filleting.
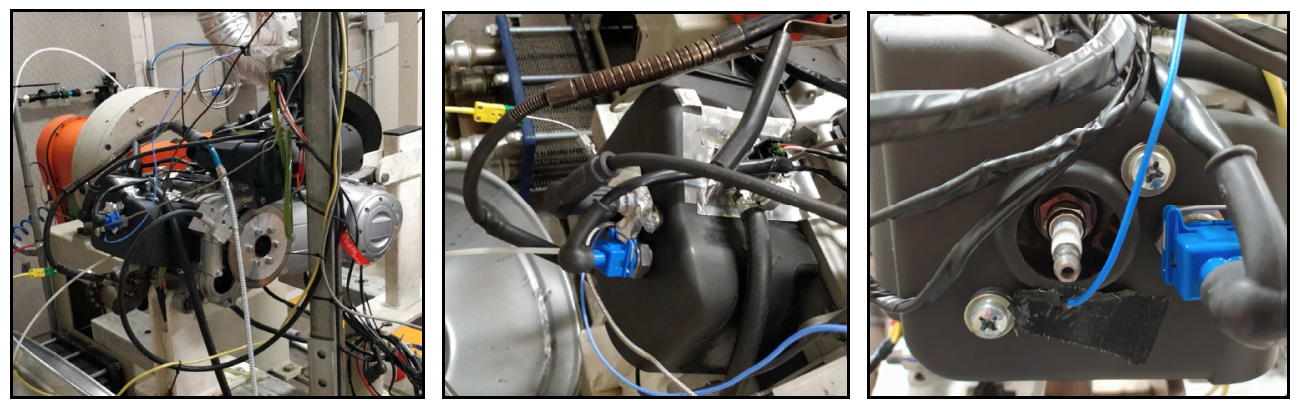

Fig. 1. Engine test-bench facility (a), LPDI injector (b), and prechamber host in the cylinder head (c).

The engine was accommodated on a 110-kW eddy current test bench of $13000 \mathrm{rpm}$ maximum speed. Torque and power measurements were carried out at the gearbox output that engages on the wheel axle so as to reduce system complexity. Average fuel mass flow measurements were carried out by means of the AVL PLUTRON CLASSIC, while CO and $\mathrm{O}_{2}$ (before the silencer) through the ASSEMBLAD INFRAGAS 309 gas analyser, in order to indirectly evaluate the average air-to-fuel ratio inside the combustion chamber and at the exhaust duct respectively. K-type and T-type thermocouples were used to measure the average temperature of the crankcase and the exhaust manifold. Average temperature and pressure in the test cell have been monitored to correct output data on standard conditions. All the average measurements were acquired through the CoBa software of the University of Florence by means of a NI Compact RIO 9024 device. An AVL GR12D piezoelectric sensor was used to measure the dynamic in-cylinder pressure, while the instantaneous angular position was registered by means of an AVL $365 \mathrm{X}$ optical encoder keyed on the crankshaft. Indicating data were acquired using the AVL IndiMicro measurement system and processed through the AVL Indicom software.

Twelve configurations of prechamber have been widely tested in order to understand the effects of the geometrical design on engine performance. The configurations differ in the number and diameter of orifices, prechamber volume, and depth of entry of the prechamber into the cylinder head (Table 1). It is worth noting that the latter characteristic reflects on the volumetric compression ratio of the engine. 
Table 1. Details of the several prechamber configurations tested during the experimental campaign.

\begin{tabular}{|c|c|c|c|c|c|}
\hline Configuration & $\begin{array}{l}\text { Orifices } \\
\text { number }\end{array}$ & $\begin{array}{c}\text { Orifices } \\
\text { diameter }[\mathrm{mm}]\end{array}$ & $\begin{array}{c}\text { Prechamber } \\
\text { volume }\left[\mathrm{mm}^{3}\right]\end{array}$ & $\begin{array}{l}\text { Total Area to } \\
\text { Volume Ratio }\end{array}$ & $\mathrm{V}_{\mathrm{P}} / \mathrm{V}_{\mathrm{C}}[\%]$ \\
\hline PC-1A & \multirow{4}{*}{4} & \multirow{4}{*}{1.2} & \multirow{2}{*}{128.43} & \multirow{2}{*}{0.035} & 2.44 \\
\hline PC-1B & & & & & 2.39 \\
\hline PC-1C & & & \multirow{2}{*}{161.61} & \multirow{2}{*}{0.028} & 3.07 \\
\hline PC-1D & & & & & 3.01 \\
\hline PC-2A & \multirow{4}{*}{4} & \multirow{4}{*}{1.5} & \multirow{2}{*}{132.62} & \multirow{2}{*}{0.053} & 2.52 \\
\hline PC-2B & & & & & 2.47 \\
\hline PC-2C & & & \multirow{2}{*}{165.80} & \multirow{2}{*}{0.043} & 3.15 \\
\hline PC-2D & & & & & 3.09 \\
\hline PC-3A & \multirow{4}{*}{6} & \multirow{4}{*}{1.2} & \multirow{2}{*}{133.46} & \multirow{2}{*}{0.051} & 2.54 \\
\hline PC-3B & & & & & 2.49 \\
\hline PC-3C & & & \multirow{2}{*}{166.65} & \multirow[t]{2}{*}{0.041} & 3.17 \\
\hline PC-3D & & & & & 3.10 \\
\hline
\end{tabular}

In details, the configuration PC-\#B is the only one which leads to the same volumetric compression ratio of the baseline engine (STD); thus, the main combustion chamber volume is reduced in order to counterbalance the additional volume of the prechamber. The configurations PC-\#A and PC-\#B have the smallest prechamber volume, while in the PC\#C and PC-\#D layouts a dedicated washer is inserted below the mechanical stop of the spark plug to increase the prechamber volume. The graphical representation of the various prechamber assemblies is presented in Table 2.

Table 2. Graphical scheme of the prechamber configurations.

\begin{tabular}{|c|c|c|c|}
\hline PC-\#A & PC-\#B & PC-\#C & PC-\#D \\
\hline 1 & 1 & 1 & 1 \\
\hline & & 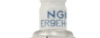 & \\
\hline$y$ & I & & \\
\hline 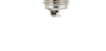 & & & \\
\hline $1=$ & 1 & $y$ & $a$ \\
\hline & & & \\
\hline & & & \\
\hline
\end{tabular}

The prechambers were manufactured of AMPCOLOY $972 \mathrm{Cu}-\mathrm{Cr}-\mathrm{Zr}$ alloy through fiveaxis milling. The selected material reflects the requirements of high thermal conductivity and resistance to high-temperature oxidation which are required for prechambers. In fact, previous analyses performed by the Authors showed the tendency of aluminium to thermal failure when using JI combustion without a dedicated cooling system (Figure 2a).

The same design criteria presented in $[23,24]$ were adopted for the prechamber layout. Direction of orifices was chosen to avoid the direct impingement of jets on the cylinder head walls; in particular, a higher slope was set toward the exhaust port due to the asymmetric shape of the cylinder head (Figure 2b). Thin washers have been used to ensure the symmetric positioning of the orifices with respect to the engine plane of symmetry. 

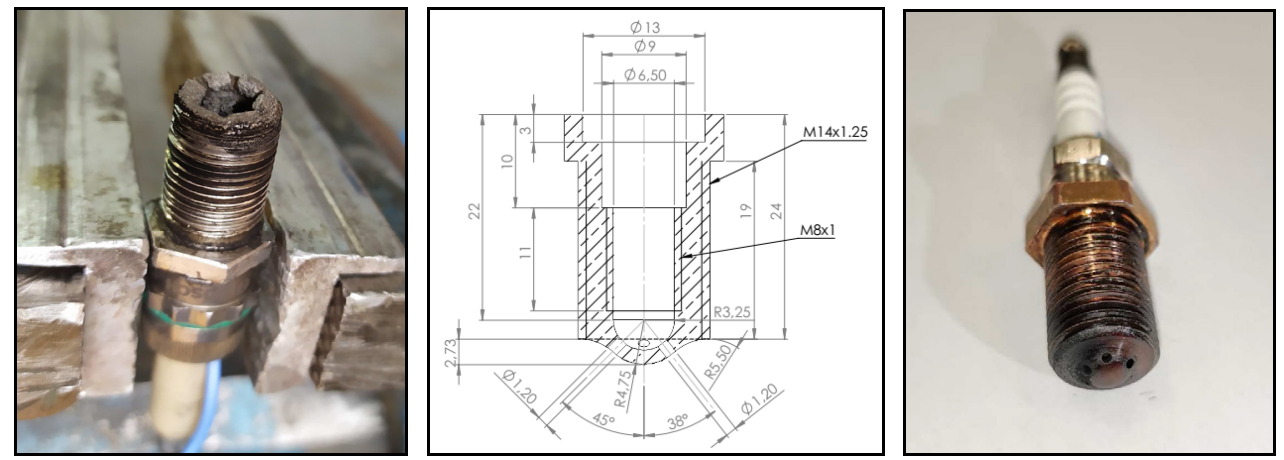

Fig. 2. Broken six-orifice aluminium prechamber (a), PC-1B drafting (b), PC-3B prechamber (c).

Three engine operating points reproducing typical motorcycle operating conditions were investigated: a) maximum torque, $6500 \mathrm{rpm}$ and full load (L3); b) $5000 \mathrm{rpm}$ and $2 \mathrm{bar}$ BMEP (L2); c) $4000 \mathrm{rpm}$ and 1 bar BMEP (L1). The two partial-load conditions were chosen based on the vehicle resistance curve. A preliminary sensitivity analysis on the PC1B prechamber was carried out by varying IGA to achieve the highest BMEP at full-load condition and the best efficiency at low loads to attain a fine-tuning of the JI engine. The PC-1B prechamber was used as the baseline JI configuration since it fully preserves the original volumetric compression ratio of the engine and requires the lowest fuel amount to develop the turbulent jets (small prechamber volume). Tests were performed by imposing different $\mathrm{CO}$ values since this parameter indicates the air/fuel ratio in $2 \mathrm{~S}$ engines. The PC1B calibrated parameters were then kept constant for all the other tested prechamber configurations to evaluate the effects of the geometrical features on the combustion process.

\section{Results}

\subsection{Sensitivity analysis on spark timing}

The preliminary experimental campaign for the fine-tuning of the JI engine was performed by studying the sole PC-1B prechamber at the three operating conditions (L1, L2, and L3).

The trend of the brake efficiency as a function of IGA at the L1 operating point (4000 rpm and 1-bar BMEP) is presented on the left side of Figure 3. The right side of Figure 3 shows instead the trend of the in-cylinder pressure (main combustion chamber) in the JI configuration by setting the four IGA values closest to the optimum.
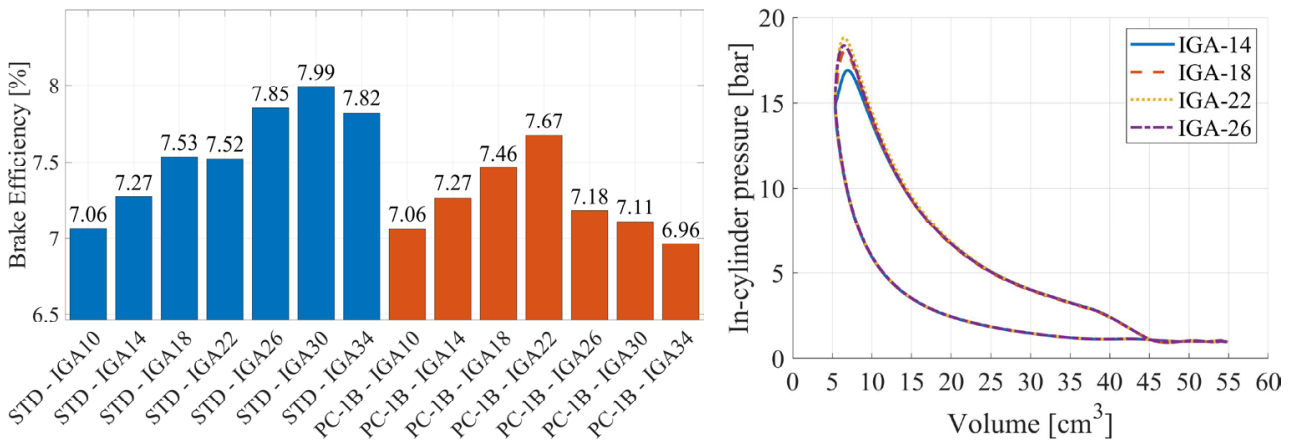

Fig. 3. Brake efficiency varying IGA at L1 condition (left); indicated P-V cycle (right). 
The two engine configurations (STD and JI) achieved the maximum brake efficiency at different IGA values; in particular, for what concern the L1 operating point, the JI engine required an $8^{\circ} \mathrm{CA}$ delayed IGA $\left(30^{\circ}\right.$ for the STD configuration and $14^{\circ}$ for the $\mathrm{PC}-1 \mathrm{~B}$ layout). This difference is essentially due to the increase in the combustion speed, which would lead to a too anticipated SOC. Both engine configurations were found to be sensitive to IGA; however, the efficiency values achieved by the JI engine were always lower than the STD configuration. It is worth noting that by anticipating the IGA value above the optimal value, the maximum pressure peak does not increase further. This behaviour clearly shows the onset of misfire phenomena.

Figure 4 on the left presents instead the effects of the variation of IGA on the brake efficiency at the L2 operating point (5000 rpm and 2-bar BMEP). Again, the trend of the incylinder pressure is shown on the right side of the Figure.
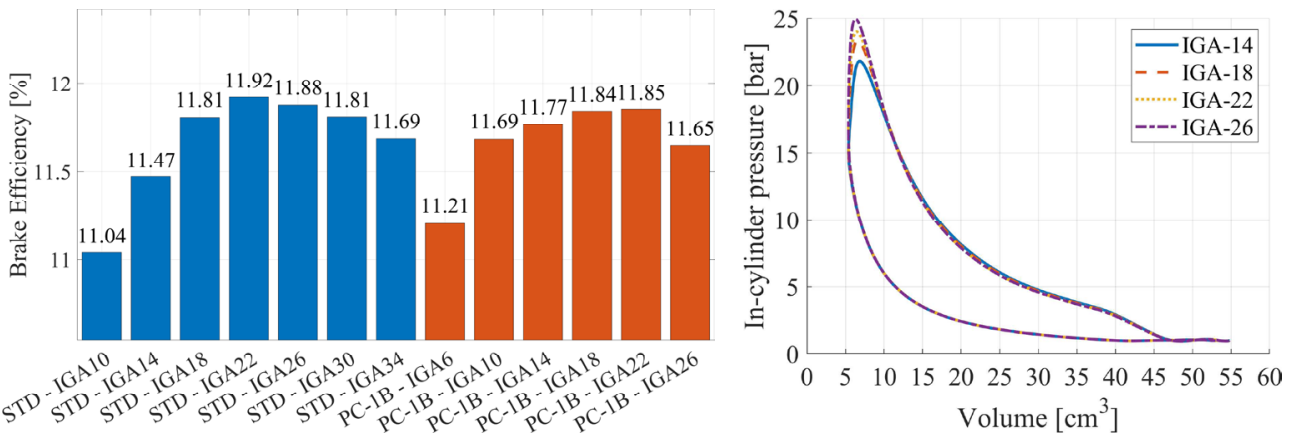

Fig. 4. Brake efficiency varying IGA at L2 condition (left); indicated P-V cycle (right).

Differently from the L1 operating point, at L2 the maximum brake efficiency was achieved by setting almost the same IGA value on both engines ( $22^{\circ}$ IGA). Moreover, in this case, the maximum pressure peak increased by anticipating the IGA value even above the optimal value. However, the JI engine was found to be less sensitive to the variation of IGA than the STD configuration. Furthermore, the JI engine by means of the PC-1B prechamber achieved almost the same efficiency of the STD engine.

For what concern the full-torque operating point (L3), in which BMEP was used as the optimisation parameter in place of the brake efficiency, the JI engine showed an almost null sensitivity to the variation of IGA (Figure 5, left). This behaviour can be explained by observing the indicated cycle of the JI engine (Figure 5, right); in fact, by delaying IGA, the smaller area related to the combustion phase in the $\mathrm{P}-\mathrm{V}$ cycle is almost compensated by the expansion phase, which occurs at a slightly higher pressure.
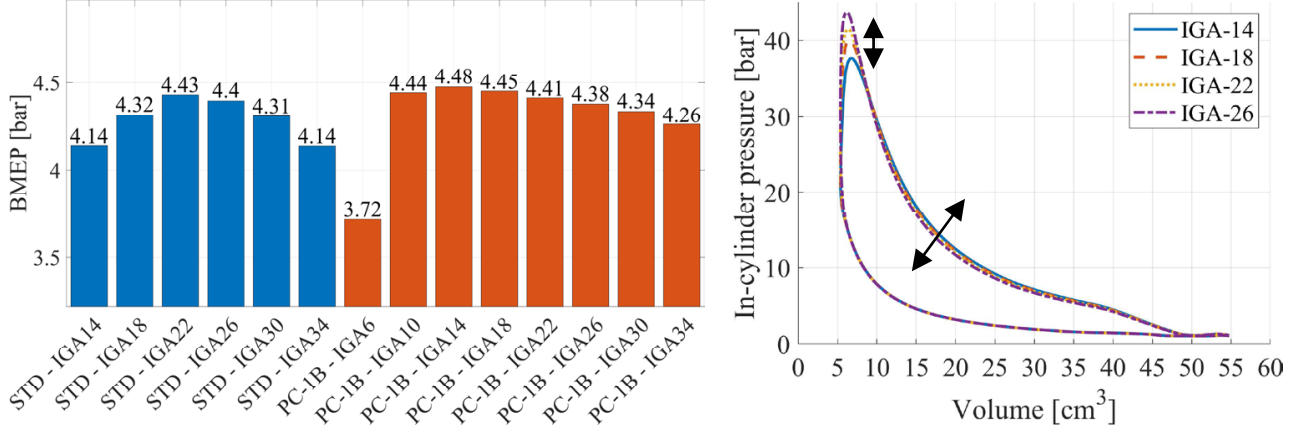

Fig. 5. BMEP for different IGA at L3 condition (left); focus on the indicated P-V cycle (right). 


\subsection{Best prechamber configurations}

During the experimental campaign, the Authors observed that it was not possible to find a unique prechamber setup capable of achieving best performance in all the operating points; in fact, results highlighted that a different prechamber configuration is required depending on the operating point.

Table 3 and Table 4 aims at evaluating the best prechamber configurations for the lowload points (L1, and L2) for different CO target values (2\% and $1.5 \%)$. The calibrated IGA values which brought to the best brake efficiency values is shown, together with the achieved brake efficiency. The throttle opening is also shown as an indicator of the engine volumetric efficiency.

Table 3. Calibrated values of IGA and best prechamber setup at operating point L1.

\begin{tabular}{|c|c|c|c|c|c|}
\hline Configuration & $\mathrm{CO}[\%]$ & IGA $\left[{ }^{\circ} \mathrm{CA}\right]$ & Eta [\%] & TPS [\%] & Best set-up \\
\hline STD & 2 & 30 & 8 & 20 & - \\
\hline STD & 1.5 & 14 & 7.5 & 26 & - \\
\hline Prechamber & 2 & 22 & 7.7 & 23 & PC-1B \\
\hline Prechamber & 1.5 & 34 & 7.7 & 25 & PC-2A \\
\hline
\end{tabular}

Table 4. Calibrated values of IGA and best prechamber setup at operating point L2.

\begin{tabular}{|c|c|c|c|c|c|}
\hline Configuration & $\mathrm{CO}[\%]$ & IGA $\left[{ }^{\circ} \mathrm{CA}\right]$ & Eta $[\%]$ & TPS [\%] & Best set-up \\
\hline STD & 2 & 22 & 11.9 & 38 & - \\
\hline STD & 1.5 & 34 & 12 & 39 & - \\
\hline Prechamber & 2 & 22 & 12.8 & 35.5 & PC-3B \\
\hline Prechamber & 1.5 & 30 & 13.1 & 36.5 & PC-3B \\
\hline
\end{tabular}

It is worth noting that the best prechamber setup not only depends on engine load and speed, but it can be related also to the CO target values. It should be noted that no evident benefits in term of efficiency were found by reducing $\mathrm{CO}$ target values at partial-load conditions (L1 and L2) in both STD and JI engines.

Evaluating instead the best prechamber configuration at full-torque condition (Table 5), it was observed that by reducing $\mathrm{CO}$ target values the JI engine increased the brake efficiency while slightly losing performance.

Table 5. Calibrated values of IGA and best prechamber setup at operating point L3.

\begin{tabular}{|c|c|c|c|c|c|}
\hline Configuration & $\mathrm{CO}[\%]$ & IGA $\left[{ }^{\circ} \mathrm{CA}\right]$ & Eta [\%] & BMEP [bar] & Best set-up \\
\hline STD & 2 & 22 & 16.6 & 4.4 & - \\
\hline STD & 1.5 & 22 & 17.9 & 4.4 & - \\
\hline Prechamber & 2 & 18 & 17 & 4.6 & PC-3B \\
\hline Prechamber & 1.5 & 14 & 17.4 & 4.4 & PC-1B \\
\hline
\end{tabular}

\subsection{Prechamber setup analysis}

A comparative study between the standard engine and the twelve JI configurations, corresponding to three different orifice setups, two different depths of insertion of the prechamber in cylinder head and two prechamber volumes, was made to evaluate the 
effects of the geometrical characteristics on combustion process and engine performance. A target $\mathrm{CO}$ of $2 \%$ was set for all the configurations since, as said before, no benefits were achieved by using leaner mixtures. Each prechamber configuration was tested at the same IGA value, depending on the operating point $\left(22{ }^{\circ} \mathrm{CA}\right.$ at $\mathrm{L} 1$ and $\mathrm{L} 2,18{ }^{\circ} \mathrm{CA}$ at L3).

\subsubsection{Operating point L1 (4000 rpm, 1-bar BMEP)}

For what concern the brake efficiency (Figure 6, left), the JI engine showed worse values respect STD configuration, no matter how the prechamber is geometrically configured, despite IGA was set to achieve the maximum brake efficiency $\left(30{ }^{\circ} \mathrm{CA}\right.$ for the standard engine compared to the $22{ }^{\circ} \mathrm{CA}$ for the JI engine). Furthermore, it can be noted that in order to achieve the same BMEP the JI engine requires a higher throttle valve opening (Figure 6, right), and thus a higher volumetric efficiency. Since the whole set of JI configurations worked with the same $\mathrm{CO}$ percentage, the increase of airflow requires a proportional increase of fuel flow; thus, it can be deduced that the decrease of performance is related to the worse average combustion efficiency .
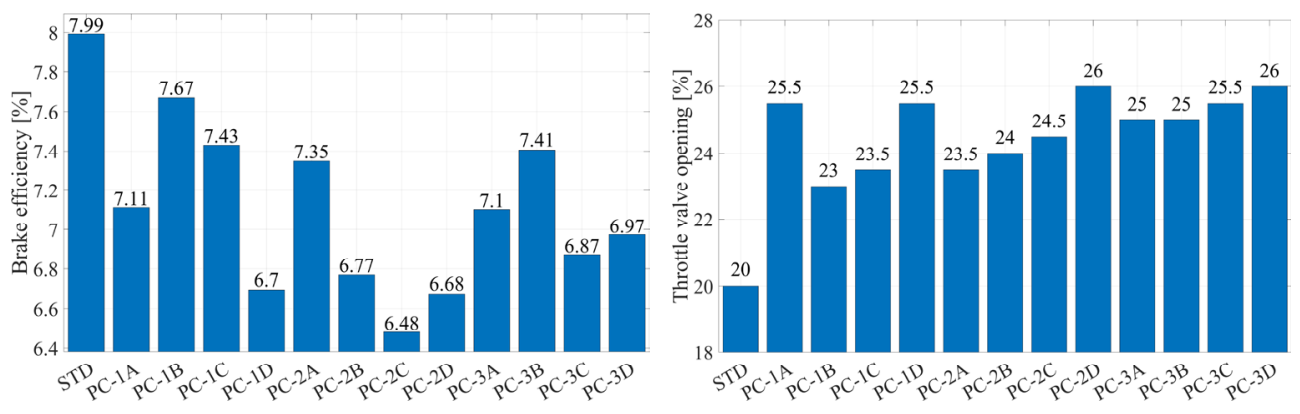

Fig. 6. Brake efficiency for the 12 tested prechambers at L1 (left) and throttle valve opening (right).

In order to understand the aforementioned behaviour, it can be useful to check the scatter plot of the in-cylinder pressure peak as a function of its position in terms of crank angle degrees (Figure 7). It can be clearly observed that the presence of misfire phenomena leads the JI engine not to adequately exploit the additional amount of fuel injected, reducing engine brake efficiency.

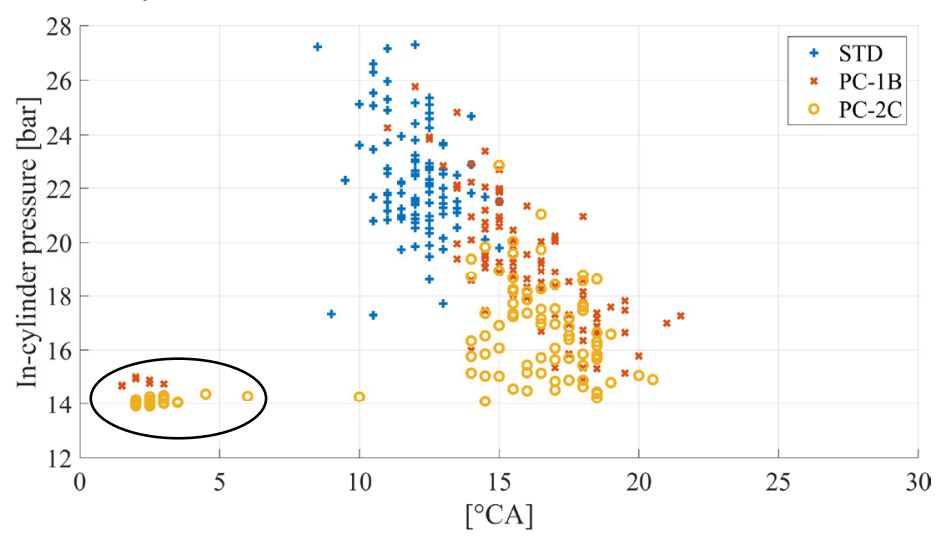

Fig. 7. Scatter plot of the pressure peak as a function of the crank angle at the $\mathrm{L} 1$ condition.

It is worth noting that at low engine load (L1) the JI engine tends to prefer small orifice prechambers (configurations PC-1\# and PC-3\#); furthermore, the engine tends to require small prechamber volumes and standard engine compression ratio (configuration $\mathrm{PC}-\# \mathrm{~B}$ ). 


\subsubsection{Operating point L2 (5000 rpm, 2-bar BMEP)}

Investigating instead the operating point L2 (5000 rpm, 2-bar BMEP), the presence of a combustion prechamber leads to a higher engine brake efficiency (Figure 8, left). In particular, a $6.6 \%$ brake efficiency improvement was achieved by means of the PC-3B prechamber configuration; good results were also achieved by using the PC-1C and PC-1A prechambers, which led to a $5.6 \%$ and $5.9 \%$ respectively higher brake efficiency. Again, results indicate that even at mid load the engine tends to require small orifice diameter. However, this time, a trend on the volume and the depth of insertion of the prechamber cannot be found. It is worth noting that the JI engine required the same IGA value of the STD engine in order to maximise the brake efficiency $\left(22^{\circ} \mathrm{CA}\right.$ for both STD and JI).

For what concern the throttle valve opening, contrarily to what happened at the operating point L1, a smaller throttle opening was required to achieve the same BMEP (Figure 8, right), thus reducing the fuel flow rate.
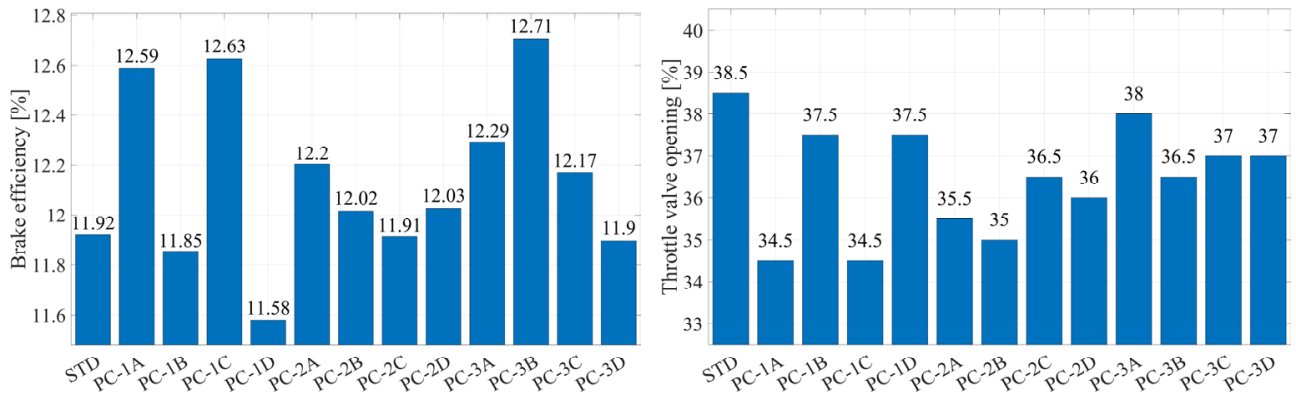

Fig. 8. Brake efficiency for the 12 tested prechambers at L2 (left) and throttle valve opening (right).

It is worth noting that the prechamber configuration that performed worst is the PC-\#D configuration (big prechamber volume, standard compression ratio), making almost null the improvements on the brake efficiency.

In fact, as it can be seen from the scatter plot (Figure 9), the PC-\#D configuration leads to a lower pressure peak and to a slower combustion phase compared to the other layouts notwithstanding the same IGA value. It should be noted that even if the PC-1D configuration leads to misfire phenomena, which caused a brake efficiency value below the STD engine, the presence of misfire is sensibly lower than the L1 operating point, which is an indication of a better scavenging of both prechamber and cylinder volumes.

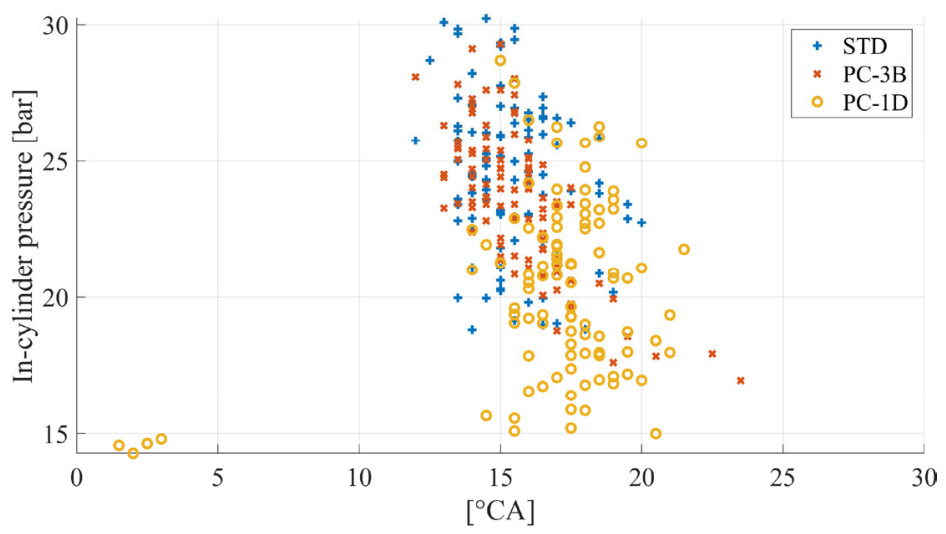

Fig. 9. Scatter plot of the pressure peak as a function of the crank angle at the L2 condition. 


\subsubsection{Operating point L3 (6500 rpm, wide open throttle)}

For what concern the full-torque point (wide open throttle, $6500 \mathrm{rpm}$ ), the JI engine has resulted in improvements of both BMEP (Figure 10, left) and brake efficiency (Figure 10, right). Greatest benefits were shown by adopting the configuration PC-3\#, i.e. the $1.2 \mathrm{~mm}$ six-orifice prechamber; in particular, the PC-3B prechamber (small prechamber volume and standard engine compression ratio) achieved the best results, leading the JI engine to a $9 \%$ higher brake efficiency and a 2,5\% higher BMEP compared to the STD engine for the same $\mathrm{CO}$ target value $(2 \%)$. It should be reminded that in order to achieve the best BMEP, the JI engine required a slightly delayed IGA $\left(18{ }^{\circ} \mathrm{CA}\right.$ compared to the $22{ }^{\circ} \mathrm{CA}$ of the STD engine).

Results suggest that the JI engine at full throttle requires bigger flow passage areas to be achieved by increasing the number orifices; this configuration may lead, in fact, to a smoother and more volumetric in-cylinder ignition, as well as a more effective scavenging and air-fuel mixture filling.
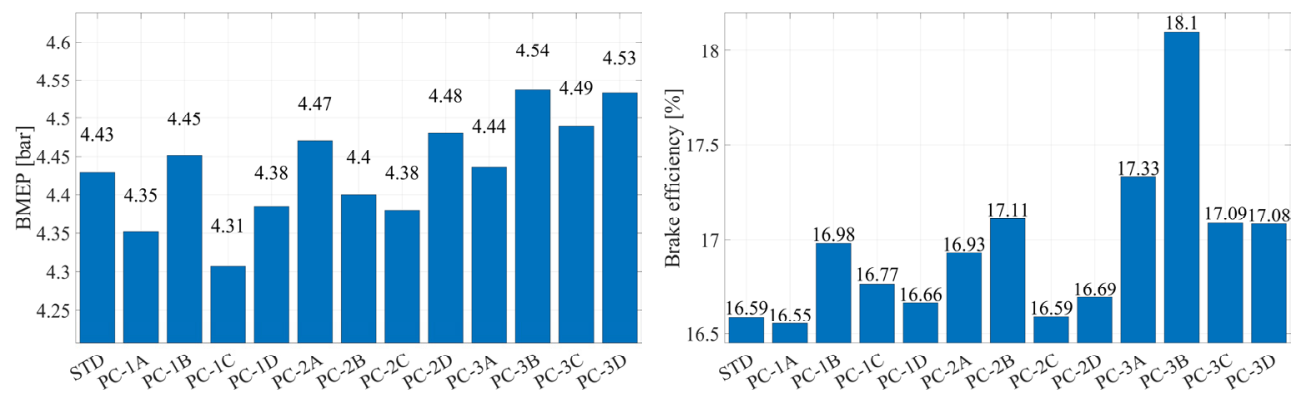

Fig. 10. BMEP values for the 12 tested prechambers at L3 (left) and brake efficiency (right).

Comparing the best, PC-3B, and the worst, PC-1C (1.2 mm four-orifice prechamber, big prechamber volume, longer depth of insertion), JI configurations in terms of combustion process, an interesting behaviour can be noted by observing the MBF S-curve (Figure 11, left). For the same IGA $\left(18{ }^{\circ} \mathrm{CA}\right)$ the PC-1C setup shows a higher combustion speed than both the PC-3B and STD configurations and the faster combustion leads to a higher pressure peak, as it can be observed from the P-V diagram (Figure 11, right). However, the in-cylinder pressure drops down in a relevant manner right after the combustion phase and along the whole expansion line, thus leading to a lower engine performance.
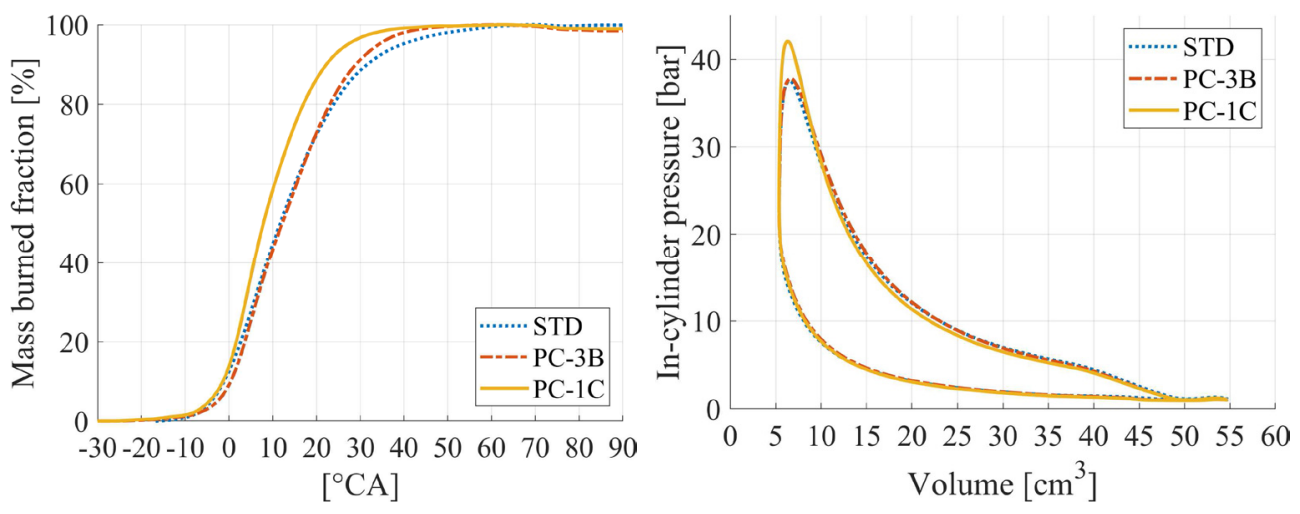

Fig. 11. S-curve of best and worst prechamber layouts at L3 (left) and pressure scatter plot (right)

This detrimental behaviour, which was already observed in previous papers concerning $2 \mathrm{~S}$ engines [14,24], leads the improvements in the combustion phase not to directly reflect 
in a better engine performance. This feature suggests that JI layouts which bring the prechamber to be more permeable to the passage of gas and thus closer to the STD engine should be preferred to "enclosed" prechambers.

\section{Discussion}

From the results it is possible to deduce the advantages and the challenges of the use of passive combustion prechambers for use in small $2 \mathrm{~S}$ engines; furthermore, it is possible to draw the guidelines that should be followed in the prechamber design in order to achieve best results depending on the target engine operating range.

For what concern the low-load low-speed operating point (L1), the prechamber setups which achieved the best results were the PC-1\# (1.2 mm four orifices) and PC-\#B (baseline volumetric compression ratio), thus indicating that the JI engine requires small prechamber volumes, which can be easily scavenged, and small flow passage areas, which increase the ignition potential of the prechamber (more strong turbulent jets). However, whatever the prechamber setup is, the achieved brake efficiency is always lower than the standard engine. This behaviour is due to the presence of the misfire phenomenon which occur for all the JI configurations and can be explained by two possible assumptions.

First, the absence of a consistent in-cylinder flow field may make insensitive the prechamber scavenging from the depth of insertion of the prechamber, which is scavenged from the downward movement of the piston only. Thus, in order to solve this issue, which is intrinsic of $2 \mathrm{~S}$ engines, and to achieve satisfactorily results at low-load and low-speed conditions, the use of an external scavenging system, i.e., an air injection in the prechamber volume, is suggested.

Second, the low in-cylinder flow field may not be adequate to transport the fuel droplets of the LPDI system close to the prechamber orifices; furthermore, it may not be able to sufficiently widespread and diffuse the fuel droplets. From this point of view, a different injector position and/or a higher injection pressure is suggested.

For what concern instead the mid-load mid-speed operating point (L2), the prechamber configuration which achieved best results were the PC-1A $(1.2 \mathrm{~mm}$ four orifices, increased compression ratio, small prechamber volume) PC-1C (1.2 mm four orifices, increased compression ratio, big prechamber volume) and PC-3B (1.2 mm six orifices, baseline compression ratio, small prechamber volume). Results clearly shows that when adopting the four-orifice prechamber the engine requires a deeper insertion in the cylinder head (and thus a higher volumetric compression ratio) in order to achieve brake efficiency values higher than the STD engine. In fact, the JI engine in the PC-1B and PC-1D setups has shown a lower brake efficiency than the STD engine. This behaviour may be attributed to the necessity of the prechamber to better intercept the in-cylinder flow field in order to scavenge the volume from internal gases; in fact, the PC-1B and PC-1D setups have shown misfire issues (Figure 9).

Adopting instead the six-orifice prechamber, the JI engine performs always better than the STD engine, even if the adoption of a smaller prechamber volume without altering the baseline engine compression ratio brought to an efficiency value even higher than the PC$1 \mathrm{~A}$ and PC-1C setups. This behaviour shows that the use of a higher number of orifices allows a better exploiting of the flow field due to the position/inclination of the transfer ducts; furthermore, the smaller amount of fuel inside the prechamber and the higher distance from the cylinder liner and piston lead the turbulent jets to reduce the heat transfer losses, thus achieving a higher engine brake efficiency.

Finally, the JI engine in the PC-2\# configuration always showed a brake efficiency close to the STD engine, indicating that the adoption of big-diameter orifices tends to reduce the effectiveness of the turbulent ignition phenomenon. 
Even at the operating point L3 (WOT), the JI engine showed best performances (in terms of BMEP), but also best efficiency values, by adopting the PC-3\# configuration. In particular, the PC-3B setup achieved a 9\% higher brake efficiency with an increase of the $2.5 \%$ of BMEP than the STD engine, indicating that the use of six orifices allows us to increase the combustion speed (Figure 11, left), thus improving the indicating and combustion efficiencies, without falling in sub-expansion issues during the expansion phase (Figure 11, right).

Instead, by using four orifices the JI engine tends to achieve BMEP values similar or even lower than the STD engine, even if the adoption of bigger orifice diameters leads to slightly better values. This behaviour explains that at WOT operations the energy potential of the turbulent jets should be reduced by increasing the number of orifices, thus achieving a more volumetric/homogenous ignition phase in the main chamber and lower heat losses.

\section{Conclusion}

In this paper the use of several passive combustion prechamber geometries on a small $2 \mathrm{~S}$ engine with LPDI fuel supply was investigated.

Based on previous experience in this field, a type of prechamber material suitable for prolonged operation without risk of oxidation, melting and generation of hot spots was sought by the Authors. In particular, AMPCOLOY $972 \mathrm{Cu}-\mathrm{Cr}-\mathrm{Zr}$ alloy was used due to the excellent compromise between temperature resistance and heat dissipation.

Three prechambers with different geometries were made, namely with four orifices of $1.2 \mathrm{~mm}$ (PC-1\#), four orifices of $1.5 \mathrm{~mm}$ (PC-2\#) and six orifices of $1.2 \mathrm{~mm}$ (PC-3\#). Two different volumes were used, $\sim 130 \mathrm{~mm}^{3}$ (PC-\#A and PC-\#B) and $\sim 160 \mathrm{~mm}^{3}$ (PC-\#C and PC-\#D). The bigger volume was achieved by inserting a washer inside the prechamber, thus removing the spark plug from the orifices. Finally, two different insertion deeps inside the cylinder head were used, in order to respect the baseline engine compression ratio (PC-\#B and PC-\#D) or to increase it (PC-\#A and PC-\#C).

The experimental campaign was then carried out at three engine operating points, in order to cover the whole operating range of the engine: low-load low-speed point, L1 (4000 rpm, 1 bar BMEP), mid-load mid-speed point, L2 (5000 rpm, 2 bar BMEP), and high-load high-speed point, L3 (WOT, $6500 \mathrm{rpm}$ ).

Results have shown that the adoption of the JI combustion bring to relevant benefits in terms of brake efficiency at both L2 and L3 operating conditions; in particular at WOT the prechamber is capable to improve engine performance also. However, the JI engine tends to suffer from misfire phenomena at the operating point L1 as a consequence of the high amount of residual gas inside the prechamber, thus resulting in a lower brake efficiency than the STD engine. This issue is particularly relevant in $2 S$ engines and difficult to be solved, since passive prechambers exploit the in-cylinder fresh charge which naturally contains a high amount of residual gas. In order to solve this issue, the use of an external scavenging system, i.e., an air injection in the prechamber volume, is suggested from the Authors, except when devices operating close to full torque are used, e.g., like garden tools.

For what concern the design guidelines for JI engines, the results suggested the adoption of six-orifice prechambers instead of four-orifice ones, since they less suffer from misfire risk and allow a more volumetric and homogenous ignition process in the main chamber, thus avoiding detrimental pressure drops in the expansion phase due to thermal losses.

Finally, it is worth noting that in small $2 \mathrm{~S}$ engines the prechamber should be designed in order to be easily scavenged and to reduce the thermal losses due to the impingement of the turbulent jets on the cylinder liner/piston; thus, small prechamber volumes should be preferred and deep prechamber insertions should be avoided. 


\section{Nomenclature}

$2 S$
BMEP
HPDI
HRR
IGA
LPDI
MBF
PFI
SO $_{\text {O }}$
SOC
SOI
STD
TDC
TPS
$\mathrm{V}_{\mathrm{C}}$
$\mathrm{V}_{\mathrm{CYL}}$
$\mathrm{V}_{\mathrm{P}}$
WOT

Two-Stroke engine

Brake Mean Effective Pressure

High-Pressure Direct Injection

Heat Release Rate

Ignition Advance (Spark Timing)

Low Pressure Direct Injection

Mass of Burned Fraction

Port Fuel Injection

Overall Flow Sectional Area

Start Of Combustion

Start Of Injection

Standard LPDI two-stroke engine

Top Dead Centre

Throttle Position Sensor

Combustion chamber volume

Cylinder displacement

Prechamber volume

Wide-Open Throttle

\section{References}

1. G. Ferrara, F. Balduzzi, and G. Vichi, in SAE 2012 World Congress \& Exhibition (SAE International, 2012)

2. F. Balduzzi, L. Romani, A. Tanganelli, S. Bigalli, and G. Ferrara, On the Effect of the Injector Position on Fuel-Air Mixture Preparation in a Two-Stroke GDI Engine (SAE International, Warrendale, PA, 2018)

3. L. Romani, F. Balduzzi, G. Ferrara, L. Bosi, R. D. Gioia, G. Bonandrini, J. Fiaschi, and F. Tozzi, Experimental Investigation on the Potentiality of a GDI System Applied to a Two-Stroke Engine: Analysis on Pollutant Emission and Fuel Consumption Reduction (SAE International, Warrendale, PA, 2018)

4. F. Balduzzi, G. Vichi, L. Romani, G. Ferrara, P. Trassi, J. Fiaschi, and F. Tozzi, SAE Int. J. Engines 8, 1885 (2015)

5. L. Romani, G. Vichi, G. Ferrara, F. Balduzzi, P. Trassi, J. Fiaschi, and F. Tozzi, Development of a Low Pressure Direct Injection System for a Small $2 S$ Engine. Part II - Experimental Analysis of the Engine Performance and Pollutant Emissions (SAE International, Warrendale, PA, 2015)

6. F. Balduzzi, G. Vichi, L. Romani, and G. Ferrara, CFD Analysis of the Effect of the Injection Pressure on a Small 2S LPDI Engine (SAE International, Warrendale, PA, 2015)

7. L. Romani, G. Vichi, F. Balduzzi, A. Bianchini, and G. Ferrara, Energy Procedia 126, 987 (2017)

8. M. Noguchi, S. Sanda, and N. Nakamura, Development of Toyota Lean Burn Engine (SAE International, Warrendale, PA, 1976)

9. T. G. Adams, Theory and Evaluation of Auxiliary Combustion (Torch) Chambers (SAE International, Warrendale, PA, 1978)

10. T. G. Adams, Torch Ignition for Combustion Control of Lean Mixtures (SAE International, Warrendale, PA, 1979) 
11. R. Latsch, The Swirl-Chamber Spark Plug: A Means of Faster, More Uniform Energy Conversion in the Spark-Ignition Engine (SAE International, Warrendale, PA, 1984)

12. J. R. C. Gomes, R. M. Valle, F. J. P. Pujatti, and J. P. Pereira, Torch Ignition System Analysis in an Spark Ignition Engine (SAE International, Warrendale, PA, 2005)

13. T. a. A. Moreira, J. G. C. Baeta, F. a. R. Filho, J. E. M. Barros, F. J. P. Pujatti, and R. Malle, Characterization of a Multi-Cylinder Torch Ignition System Operating with Homogenous Charge and Lean Mixture (SAE International, Warrendale, PA, 2014)

14. A. K. Hayashi, K. Matsuura, and S. Baba, Performance of a Flame Jet Ignition System in a Two-Stroke Engine (SAE International, Warrendale, PA, 2000)

15. S. Yamaguchi, N. Ohiwa, and T. Hasegawa, Combustion and Flame 59, 177 (1985)

16. M. Konishi, N. Nakamura, E. Oono, T. Baika, and S. Sanda, Effects of a Prechamber on NOx Formation Process in the SI Engine (SAE International, Warrendale, PA, 1979)

17. N. S. Mavinahally, D. N. Assanis, K. R. Govinda Mallan, and K. V. Gopalakrishnan, J. Eng. Gas Turbines Power 116, 793 (1994)

18. V. Weng, J. Gindele, G. Töpfer, U. Spicher, R. Latsch, and D. Kuhnert, Investigation of the Bowl-Prechamber-Ignition (BPI) Concept in a Direct Injection Gasoline Engine at Part Load (SAE International, Warrendale, PA, 1999)

19. M. Kettner, J. Fischer, A. Nauwerck, J. Tribulowski, U. Spicher, A. Velji, D. Kuhnert, and R. Latsch, The BPI Flame Jet Concept to Improve the Inflammation of Lean Burn Mixtures in Spark Ignited Engines (SAE International, Warrendale, PA, 2004)

20. M. Kettner, M. Rothe, A. Velji, U. Spicher, D. Kuhnert, and R. Latsch, A New Flame Jet Concept to Improve the Inflammation of Lean Burn Mixtures in SI Engines (SAE International, Warrendale, PA, 2005)

21. L. Fu, T. Ishima, W. Long, and J. Tian, JTST 4, 53 (2009)

22. M. Chiodi, A. Kaechele, M. Bargende, D. Wichelhaus, and C. Poetsch, SAE Int. J. Engines 10, 2486 (2017)

23. M. Ciampolini, S. Bigalli, F. Balduzzi, A. Bianchini, L. Romani, and G. Ferrara, Energies 13, 2846 (2020)

24. L. Bosi, M. Ciampolini, L. Romani, F. Balduzzi, and G. Ferrara, Experimental Analysis on the Effects of Passive Prechambers on a Small 2-Stroke Low-Pressure Direct Injection (LPDI) Engine (SAE International, Warrendale, PA, 2020) 